УДК 681.5.001.63: 629.1.098: 621.9.048

\author{
О. М. Мирошник, к.т.н., дочент, \\ доцент кафедри пожежної тактики та аварійно-рятувальних робіт \\ e-mail: omiroshnik@ukr.net \\ Черкаський інститут пожежної безпеки імені Героїв Чорнобиля НУЦЗ України \\ вул. Онопрієнка, 8, м. Черкаси, 18034, Україна
}

\title{
ТЕХНОЛОГІЯ ЕКСПЕРТНОГО ВИЗНАЧЕННЯ РІВНЯ ТЕХНОГЕННОЇ БЕЗПЕКИ ЖИТЛА У БУДИНКАХ ПІДВИЩЕНОЇ ПОВЕРХОВОСТІ
}

У статті розглядається задача визначення рівня техногенної безпеки житла у будинках підвищеної поверховості. Запропоновано для визначення пріоритетності факторів, що впливають на безпеку житла та є аргументами відповідної иільової функиії, використати експертне оцінювання, елементи методу аналізу ієрархій і теорії нечітких множин. Визначено особливості індивідуального та групового експертного оцінювання.

Ключові слова: рівень техногенної безпеки, надзвичайна ситуація, експертне оцінювання.

Вступ. Низька поінформованість населення про рівень техногенної безпеки житла в будинках підвищеної поверховості (БПП) та, як результат, неадекватність його ціни і безпекових характеристик визначають актуальність розробки технології та інформаційноконсультативного супроводу суб'єктів ринку нерухомості (будівельних та страхових компаній, жителів, працівників пожежного захисту). Одним із ії важливих елементів є визначення рівня техногенної безпеки житла у БПП. Певні кроки у цьому напрямку вже були зроблені раніше. Зокрема, дисертаційне дослідження О. М. Джулая [1] присвячене визначенню рівня пожежної безпеки як залежності

$$
R=f(X, Z),
$$

де $R$ - рівень пожежної безпеки, $X$ - множина внутрішніх факторів, $Z$ - множина зовнішніх характеристик.

Ідентифікація залежності (1) здійснювалася на основі статистичної інформації 3 використанням регресійного аналізу [2], методу групового врахування аргументів [3], нейронних мереж [4].

Більш глибокий аналіз предметної області запропоновано у статті [5]. Автор пропонує розширити множину факторів, які враховуються при визначенні рівня пожежної безпеки житла у багатоповерхових житлових будинках. Відповідна модель є такою:

$$
R=g\left(X_{k}, Z_{k}, P_{1}, P_{2}, k\right)
$$

де $X_{k}-$ множина внутрішніх факторів, які впливають на безпеку житла, $Z_{k}-$ множина відповідних зовнішніх характеристик, $P_{1}-$ ймовірність бути травмованим на пожежі, $P_{2}$ - ймовірність загинути від пожежі, $k$ - номер поверху житла. Модель (2) є точнішою, оскільки для мешканців ймовірності $P_{1}, P_{2}$ та номер поверху є важливими факторами при визначенні безпечності житла.

Вихідні дані та постановка задачі. Результати, які одержуються при використанні моделей (1) та (2), становлять аналітичне підгрунтя процесів прийняття рішень при будівництві та купівлі житла. Водночас, необхідно зазначити недоліки цих моделей. Значна кількість внутрішніх факторів і зовнішніх характеристик не дозволяє встановити пріоритети як емпірично, так i аналітично. Адекватний аналіз такої кількості факторів можливий за умов проведення препроцесінгу даних [6], визначення їх інформативності та значущості [7], що вимагає значних інтелектуальних зусиль і обчислювальних затрат. Крім того, в моделях (1) та (2) не враховано такий фактор, як кількість пожеж на певних поверхах та можливість виникнення надзвичайної ситуації зовні будівлі. Вказані вище недоліки свідчать про необхідність розв'язання задачі визначення пріоритетності факторів, які використовуються для встановлення рівня техногенної безпеки житла БПП, як умови об'єктивізації відповідних процесів прийняття рішень.

Таким чином, метою роботи є підвищення ефективності процесів прийняття рішень суб'єктами ринку нерухомості та надання їм інформаційно-консультативного супроводу шляхом розробки технології експертного 
визначення рівня техногенної безпеки житла у будинках підвищеної поверховості.

Метод визначення пріоритетів факторів на основі аналізу ісрархій та суб'сктивних висновків

Після уточнень моделі (1) та (2) модифікуються до такого виду:

$$
R^{k}=h\left(X_{k}, Z_{k}, P_{1}^{k}, P_{2}^{k}, P_{3}^{k}\right),
$$

де $R^{k}$ - рівень техногенної безпеки житла у БПП на $k$-му поверсі, $X_{k}, Z_{k}$ - внутрішні фактори та зовнішні характеристики для $k$-го поверху, $P_{1}^{k}, P_{2}^{k}, P_{3}^{k}$ - ймовірності бути травмованим, загинути та виникнення пожежі на $k$ му поверсі, відповідно. Визначимо пріоритети вищезазначених аргументів моделі (3) за методом аналізу ієрархій Т. Сааті [8]. На першому етапі шляхом експертного опитування формуємо матрицю $\Xi=\left\{\theta_{\mathrm{ij}}, i, j=\overline{1,5}\right\}$,

$$
\Xi=\begin{array}{cccccc} 
& \boldsymbol{X}_{\boldsymbol{k}} & \boldsymbol{Z}_{\boldsymbol{k}} & \boldsymbol{P}_{1}^{\boldsymbol{k}} & \boldsymbol{P}_{2}^{\boldsymbol{k}} & \boldsymbol{P}_{3}^{\boldsymbol{k}} \\
\boldsymbol{X}_{\boldsymbol{k}} & \theta_{11} & \theta_{12} & \theta_{13} & \theta_{14} & \theta_{15} \\
\boldsymbol{Z}_{\boldsymbol{k}} & \theta_{21} & \theta_{22} & \theta_{23} & \theta_{24} & \theta_{25} \\
\boldsymbol{P}_{1}^{\boldsymbol{k}} & \theta_{31} & \theta_{32} & \theta_{33} & \theta_{34} & \theta_{35} \\
\boldsymbol{P}_{2}^{\boldsymbol{k}} & \theta_{41} & \theta_{42} & \theta_{43} & \theta_{44} & \theta_{45} \\
\boldsymbol{P}_{3}^{\boldsymbol{k}} & \theta_{51} & \theta_{52} & \theta_{53} & \theta_{54} & \theta_{55}
\end{array}
$$

В матриці $\Xi$ значення $\theta_{i j} \in\{1,2, . ., 9\}$,

де

1 - означає, що $i$-й та $j$-й фактори однаково важливі;

3 - $i$-й фактор незначно важливіший, ніж $j$-й фактор;

5 - $i$-й фактор значно важливіший, ніж $j$-й фактор; фактор;

7 - $i$-й фактор явно важливіший, ніж $j$-й

$9-i$-й фактор абсолютно важливіший, ніж $j$-й фактор.

Матриця $\Xi є$ обернено симетричною, тобто $\theta_{i j}=1 / \theta_{j i}, \boldsymbol{i}, \boldsymbol{j}=\overline{1,5}$. Вагові коефіцієнти факторів $\left(X_{k}, Z_{k}, P_{1}^{k}, P_{2}^{k}, P_{3}^{k}\right)$ визначаються як координати власного вектора матриці $\Xi$, який відповідає максимальному власному числу і знаходиться із системи рівнянь

$$
\left\{\begin{array}{l}
\Xi \cdot V=\lambda_{\max } \cdot V, \\
v_{1}+v_{2}+\ldots v_{5}=1,
\end{array}\right.
$$

де $V$ - відповідний власний вектор, $V=\left(v_{1}, v_{2}, v_{3}, v_{4}, v_{5}\right), \lambda_{\text {max }}-$ максимальне власне число матриці $\Xi$. Зауважено, що елементи множин $X_{k}$ та $Z_{k}$ необхідно розглядати 3 позиції їх виливу на техногенну безпеку житла.

Розв'язок системи (4) дозволить знайти пріоритети факторів (груп факторів), що впливають на рівень техногенної безпеки, для одного експерта. Безумовно, такий розв' язок $\epsilon$ важливим інформативним фактором, якщо експерт i $\epsilon$ особою, що приймає рішення (ОПР), оскільки вона, маючи або розрахувавши кількісні дані, що визначають елементи вибору $\left(X_{k}, Z_{k}, P_{1}^{k}, P_{2}^{k}, P_{3}^{k}\right)$, зможе використовувати кількісні оцінки переваг у процесі прийняття рішень.

Розглядаючи проблему з вищого ієрархічного рівня, зауважимо, що розв'язок (4) $є$ суб'єктивованим. Його не можна використати при визначенні загальних тенденцій будівництва, цінової політики та рекомендацій щодо забезпечення техногенної безпеки житла у БПП, оскільки такий розв'язок найчастіше $\epsilon$ зміщеним.

Модифікація схеми Беллмана-Заде для визначення пріоритетності факторів

Для об'єктивізації значень пріоритетів факторів, що впливають на безпеку житла, модифікуємо схему Беллмана-Заде [9]. Задачу сформулюємо наступним чином.

Позначимо $\left(X_{k}, Z_{k}, P_{1}^{k}, P_{2}^{k}, P_{3}^{k}\right)=$ $=\left(Y_{1}, Y_{2}, Y_{3} Y_{4} Y_{5}\right)=Y-$ множину факторів, які підлягають аналізу, $A=\left(A_{1}, A_{2}, \ldots, A_{n}\right)$ - множина експертів, які будуть оцінювати фактори та визначати їх пріоритетність. Задача експертного оцінювання полягає у впорядкуванні елементів $Y$ за висновками експертів $3 E$.

Метод розв'язання задачі матиме такі кроки:

Крок 1. Формуємо матриці попарних порівнянь $\Xi_{k}, k=\overline{1,4}$ для кожного експерта, в яких будуть знаходитись порівняльні оцінки елементів $Y, \Xi_{k}=\left\{\theta_{i j}^{k} \mid k=\overline{1, n}, i, j=\overline{1,5}\right\}$.

Крок 2. Для констант матриці $\Xi_{k}$ знаходимо власний вектор $V_{k}$, що відповідає максимальному власному числу $\lambda_{\text {max }}^{k}, k=\overline{1, n}$. 
Крок 3. Позначимо $\mu_{E_{i}}\left(Y_{j}\right)$ - число із $[0,1]$, що вказує на оцінку пріоритетності фактора $Y_{j}$ експертом $E_{i}, j=\overline{1,5}, i=\overline{1,4}, \mu_{E_{i}}\left(Y_{j}\right)=v_{i j}$. Тоді висновки експерта $E_{i}$ подаємо як нечітку множину $\tilde{E}_{i}$, визначену на універсальній множині $\mathrm{Y}$, тобTо

$$
\tilde{E}_{i}=\left\{\frac{\mu_{E_{i}}\left(Y_{1}\right)}{Y_{1}} ; \frac{\mu_{E_{i}}\left(Y_{2}\right)}{Y_{2}} ; \frac{\mu_{E_{i}}\left(Y_{3}\right)}{Y_{3}} ; \frac{\mu_{E_{i}}\left(Y_{4}\right)}{Y_{4}} ; \frac{\mu_{E_{i}}\left(Y_{5}\right)}{Y_{5}}\right\} \text {. }
$$

Крок 4. Оскільки оптимальним $\epsilon$ розв'язок, який одночасно найкращий для усіх експертів, то, враховуючи положення теорії нечітких множин [9], знаходимо його як перетин часткових експертних висновків

$$
\tilde{E}=\bigcap_{i=1}^{n} \tilde{E}_{i}=\left\{\frac{\min _{i=1, n} \mu_{E_{i}}\left(Y_{1}\right)}{Y_{1}} ; \frac{\min _{i=1, n} \mu_{E_{i}}\left(Y_{2}\right)}{Y_{2}} ; \ldots . . ; \frac{\min _{i=1, n} \mu_{E_{i}}\left(Y_{5}\right)}{Y_{5}}\right\} .
$$

Крок 5. Нормуючи значення, які знаходяться в чисельниках (6), одержимо об'єктивовані пріоритетності факторів, що впливають на техногенну безпеку житла.

Очевидно, що експерти, які беруть участь у процесі оцінювання пріоритетності факторів, мають різну компетентність і виникає необхідність ії визначення. Існує багато підходів до розв'язання цієї задачі [10]. Найчастіше використовуються два 3 них. У першому випадку рішення про компетентність експертів приймає ОПР на основі наявної інформації з використанням, наприклад, методу аналізу ієрархій [8]. Якщо ж така інформація відсутня, то можна застосувати метод визначення компетентності експертів на основі аксіоми незміщеності [11]. Роль ОПР у другому випадку зводиться до формування тестових питань для експертів.

Оптимальний розв'язок у такому випадку знаходиться як перетин

$$
\tilde{E}=\bigcap_{i=1}^{n} \tilde{E}_{i}=\left\{\begin{array}{l}
\frac{\min _{i=1, n}\left(\mu_{E_{i}}\left(Y_{1}\right)\right)^{\alpha_{i}}}{Y_{1}} ; \frac{\min \left(\mu_{E_{i}}\left(Y_{2}\right)\right)^{\alpha_{i}}}{Y_{2}} ; . . \\
. ; \frac{\min _{i=1, n}\left(\mu_{E_{i}}\left(Y_{5}\right)\right)^{\alpha_{i}}}{Y_{5}}
\end{array}\right\} .
$$

\section{Експериментальна верифікація}

Розглянемо особливості реалізації запропонованої технології. Припустимо, що експерт є один. Оскільки значення матриці $\Xi$ задаються суб'єктивно, то існує значна ймовірність того, що вони будуть погано узгодженими. Тому експерт задає лише один рядок матриці (у нашому випадку - перший), а елементи інших рядків розраховуються за формулою

$$
a_{i j}=\frac{a_{1 j}}{a_{1 i}}, i, j, k=\overline{1,5} .
$$

Нехай матриця попарних порівнянь факторів $€$ такою:

$$
\Xi=\begin{array}{cccccc} 
& \boldsymbol{X}_{\boldsymbol{k}} & \boldsymbol{Z}_{\boldsymbol{k}} & \boldsymbol{P}_{1}^{k} & \boldsymbol{P}_{2}^{k} & \boldsymbol{P}_{3}^{k} \\
\boldsymbol{X}_{\boldsymbol{k}} & 1 & 1 / 2 & 1 / 3 & 1 / 9 & 1 / 8 \\
\boldsymbol{Z}_{\boldsymbol{k}} & 2 & 1 & 2 / 3 & 2 / 9 & 1 / 4 \\
\boldsymbol{P}_{1}^{k} & 3 & 3 / 2 & 1 & 1 / 3 & 3 / 8 \\
\boldsymbol{P}_{2}^{k} & 9 & 9 / 2 & 3 & 1 & 9 / 8 \\
\boldsymbol{P}_{3}^{k} & 8 & 4 & 8 / 3 & 8 / 9 & 1
\end{array} .
$$

Розв'язуючи задачу (4), одержимо вектор пріоритетів - $(0,04 ; 0,08 ; 0,13 ; 0,39 ; 0,35)$. У випадку, коли висновки про важливість факторів робить група експертів, формуємо множину таблиць:

$$
\begin{aligned}
& \begin{array}{lllll}
\boldsymbol{X}_{\boldsymbol{k}} & \boldsymbol{Z}_{\boldsymbol{k}} & \boldsymbol{P}_{1}^{\boldsymbol{k}} & \boldsymbol{P}_{2}^{\boldsymbol{k}} & \boldsymbol{P}_{3}^{\boldsymbol{k}}
\end{array} \\
& \begin{array}{llllll}
\boldsymbol{X}_{\boldsymbol{k}} & 1 & 1 / 3 & 1 / 4 & 1 / 8 & 1 / 8
\end{array} \\
& \Xi_{1}=\begin{array}{cccccc}
\boldsymbol{Z}_{\boldsymbol{k}} & 3 & 1 & 3 / 4 & 3 / 8 & 3 / 8 \\
\boldsymbol{P}_{1}^{k} & 4 & 4 / 3 & 1 & 1 / 2 & 1 / 2
\end{array}, \\
& \begin{array}{llllll}
\boldsymbol{P}_{2}^{k} & 8 & 8 / 3 & 2 & 1 & 1
\end{array} \\
& \begin{array}{llllll}
\boldsymbol{P}_{3}^{k} & 8 & 8 / 3 & 2 & 1 & 1
\end{array} \\
& \begin{array}{lllll}
\boldsymbol{X}_{\boldsymbol{k}} & \boldsymbol{Z}_{\boldsymbol{k}} & \boldsymbol{P}_{1}^{\boldsymbol{k}} & \boldsymbol{P}_{2}^{\boldsymbol{k}} & \boldsymbol{P}_{3}^{\boldsymbol{k}}
\end{array} \\
& \begin{array}{llllll}
X_{k} & 1 & 1 / 4 & 1 / 4 & 1 / 8 & 1 / 9
\end{array} \\
& \Xi_{2}=\begin{array}{llllll}
\boldsymbol{Z}_{\boldsymbol{k}} & 4 & 1 & 1 & 1 / 2 & 4 / 9 \\
\boldsymbol{P}_{1}^{k} & 4 & 1 & 1 & 1 / 2 & 4 / 9
\end{array}, \\
& \begin{array}{llllll}
\boldsymbol{P}_{2}^{k} & 8 & 2 & 2 & 1 & 8 / 9
\end{array} \\
& \begin{array}{llllll}
\boldsymbol{P}_{3}^{k} & 9 & 9 / 4 & 9 / 4 & 9 / 8 & 1
\end{array}
\end{aligned}
$$

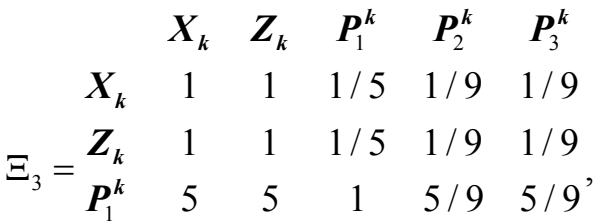

$$
\begin{aligned}
& \begin{array}{llllll}
\boldsymbol{P}_{2}^{k} & 9 & 9 & 9 / 5 & 1 & 1
\end{array} \\
& \begin{array}{llllll}
\boldsymbol{P}_{3}^{\boldsymbol{k}} & 9 & 9 & 9 / 5 & 1 & 1
\end{array} \\
& \begin{array}{lllll}
\boldsymbol{X}_{\boldsymbol{k}} & \boldsymbol{Z}_{\boldsymbol{k}} & \boldsymbol{P}_{1}^{\boldsymbol{k}} & \boldsymbol{P}_{2}^{\boldsymbol{k}} & \boldsymbol{P}_{3}^{\boldsymbol{k}}
\end{array} \\
& \begin{array}{llllll}
\boldsymbol{X}_{k} & 1 & 1 / 2 & 1 / 3 & 1 / 7 & 1 / 9
\end{array} \\
& \Xi_{4}=\begin{array}{cccccc}
\boldsymbol{Z}_{\boldsymbol{k}} & 2 & 1 & 2 / 3 & 2 / 7 & 2 / 9 \\
\boldsymbol{P}_{1}^{k} & 3 & 3 / 2 & 1 & 3 / 7 & 1 / 3
\end{array} . \\
& \begin{array}{llllll}
\boldsymbol{P}_{2}^{k} & 7 & 7 / 2 & 7 / 3 & 1 & 7 / 9
\end{array} \\
& \begin{array}{llllll}
\boldsymbol{P}_{3}^{k} & 9 & 9 / 2 & 3 & 9 / 7 & 1
\end{array}
\end{aligned}
$$


Після розрахунків одержимо:

$$
\begin{aligned}
& \boldsymbol{V}_{1}=(0,04 ; 0,13 ; 0,17 ; 0,33 ; 0,33), \\
& \boldsymbol{V}_{2}=(0,04 ; 0,02 ; 0,18 ; 0,36 ; 0,40), \\
& \boldsymbol{V}_{3}=(0,04 ; 0,04 ; 0,20 ; 0,36 ; 0,36), \\
& \boldsymbol{V}_{4}=(0,05 ; 0,09 ; 0,14 ; 0,32 ; 0,41) .
\end{aligned}
$$

Таким чином, експертні висновки можна записати як нечіткі множини:

$$
\begin{aligned}
& \widetilde{E}_{1}=\left\{\frac{0,04}{X_{k}} ; \frac{0,13}{Z_{k}} ; \frac{0,17}{P_{1}^{k}} ; \frac{0,33}{P_{2}^{k}} ; \frac{0,33}{\left.P_{3}^{k}\right\}} ;\right. \\
& \widetilde{E}_{2}=\left\{\frac{0,04}{X_{k}} ; \frac{0,02}{Z_{k}} ; \frac{0,18}{P_{1}^{k}} ; \frac{0,36}{P_{2}^{k}} ; \frac{0,40}{P_{3}^{k}}\right\} ; \\
& \widetilde{E}_{3}=\left\{\frac{0,04}{X_{k}} ; \frac{0,04}{Z_{k}} ; \frac{0,20}{P_{1}^{k}} ; \frac{0,36}{P_{2}^{k}} ; \frac{0,36}{P_{3}^{k}}\right\} ; \\
& \widetilde{E}_{4}=\left\{\frac{0,05}{X_{k}} ; \frac{0,09}{Z_{k}} ; \frac{0,14}{P_{1}^{k}} ; \frac{0,32}{P_{2}^{k}} ; \frac{0,41}{P_{3}^{k}}\right\} ;
\end{aligned}
$$

Результатом $є$ нечітка множина

$\tilde{\boldsymbol{E}}=\left\{\frac{0,04}{\boldsymbol{X}_{\boldsymbol{k}}} ; \frac{0,02}{\boldsymbol{Z}_{\boldsymbol{k}}} ; \frac{0,14}{\boldsymbol{P}_{1}^{\boldsymbol{k}}} ; \frac{0,32}{\boldsymbol{P}_{2}^{\boldsymbol{k}}} ; \frac{0,33}{\boldsymbol{P}_{3}^{\boldsymbol{k}}}\right\}$.

Остаточний результат після формування і є пріоритетами факторів:

$$
\boldsymbol{V}=(0,05 ; 0,02 ; 0,16 ; 0,38 ; 0,39\} .
$$

Якщо припустити, що експерти мають компетентності, вказані у векторі $\alpha=\left(\alpha_{1}, \alpha_{2}, \alpha_{3}, \alpha_{4},\right)=(0,2 ; 0,3 ; 0,4 ; 0,1), \quad$ то нечіткі множини будуть такими:

$$
\begin{aligned}
& E_{1}=\left\{\frac{0,04^{0,2}}{X_{k}} ; \frac{0,13^{0,2}}{Z_{k}} ; \frac{0,17^{0,2}}{P_{1}^{k}} ; \frac{0,33^{0,2}}{P_{2}^{k}} ; \frac{0,33^{0,2}}{P_{3}^{k}}\right\}= \\
& =\left\{\frac{0,53}{X_{k}} ; \frac{0,66}{Z_{k}} ; \frac{0,7}{P_{1}^{k}} ; \frac{0,8}{P_{2}^{k}} ; \frac{0,8}{P_{3}^{k}}\right\} ; \\
& E_{2}=\left\{\frac{0,04^{0,3}}{X_{k}} ; \frac{0,02^{0,3}}{Z_{k}} ; \frac{0,18^{0,3}}{P_{1}^{k}} ; \frac{0,36^{0,3}}{P_{2}^{k}} ; \frac{0,4^{0,3}}{P_{3}^{k}}\right\}= \\
& =\left\{\frac{0,38}{X_{k}} ; \frac{0,316}{Z_{k}} ; \frac{0,6}{P_{1}^{k}} ; \frac{0,74}{P_{2}^{k}} ; \frac{0,76}{P_{3}^{k}}\right\} ; \\
& E_{3}=\left\{\frac{0,04^{0,4}}{X_{k}} ; \frac{0,04^{0,4}}{Z_{k}} ; \frac{0,2^{0,4}}{P_{1}^{k}} ; \frac{0,36^{0,4}}{P_{2}^{k}} ; \frac{0,36^{0,4}}{P_{3}^{k}}\right\}= \\
& =\left\{\frac{0,28}{X_{k}} ; \frac{0,28}{Z_{k}} ; \frac{0,53}{P_{1}^{k}} ; \frac{0,67}{P_{2}^{k}} ; \frac{0,67}{P_{3}^{k}}\right\} ; \\
& E_{4}=\left\{\frac{0,05^{0,1}}{X_{k}} ; \frac{0,09^{0,1}}{Z_{k}} ; \frac{0,14^{0,1}}{P_{1}^{k}} ; \frac{0,32}{P_{2}^{k}} ; \frac{0,43}{P_{3}^{k}}\right\}= \\
& =\left\{\frac{0,74}{X_{k}} ; \frac{0,79}{Z_{k}} ; \frac{0,82}{P_{1}^{k}} ; \frac{0,89}{P_{2}^{k}} ; \frac{0,91}{P_{3}^{k}}\right\} .
\end{aligned}
$$

У результаті перетину множин $\tilde{E}_{i}, i=\overline{1,4}$, одержимо

$$
\begin{aligned}
& \tilde{E}=\left\{\frac{0,28}{X_{k}} ; \frac{0,28}{Z_{k}} ; \frac{0,53}{P_{1}^{k}} ; \frac{0,67}{P_{2}^{k}} ; \frac{0,67}{P_{3}^{k}}\right\}, \\
& \text { або після нормування } \\
& E=\left\{\frac{0,12}{X_{k}} ; \frac{0,12}{Z_{k}} ; \frac{0,22}{P_{1}^{k}} ; \frac{0,28}{P_{2}^{k}} ; \frac{0,28}{P_{3}^{k}}\right\} .
\end{aligned}
$$

Таким чином, одержано вектор пріоритетів факторів $V=\{0,12 ; 0,12 ; 0,22 ; 0,28 ; 0,28\}$.

Результати експериментів вказують на значну дисперсію пріоритетів, визначених одним експертом, групою рівнокомпетентних експертів та експертів із різним рівнем компетентності. Зокрема, найбільш поляризованими $\epsilon$ висновки одного експерта та групи експертів 3 однаковою компетентністю. Їх аналіз свідчить про розбіжність суджень про рівень впливу внутрішніх факторів та зовнішніх характеристик на стан техногенної безпеки житла у БПП. Разом із цим майже однаковим $\epsilon$ їх висновки про значний вплив кількості травмованих на пожежах на рівень безпеки (у 23 рази більший, ніж вплив внутрішніх факторів та зовнішніх характеристик). I приблизно ще у три рази вплив ймовірності виникнення пожежі та ймовірності загинути на пожежі переважає вплив ймовірності бути травмованим.

Висновки і перспективи. Запропонована технологія та проведені експериментальні дослідження $є$ важливим кроком до вдосконалення процесу інформаційноаналітичного забезпечення суб'єктів ринку нерухомості у напрямку визначення рівня техногенної безпеки житла у БПП. Одержані результати дозволяють здійснювати кількісні порівняння якісних факторів, що впливають на рівень техногенної безпеки житла, та визначати домінуючі безпекові характеристики. Ще одним важливим наслідком розробленої технології є можливість об'єктивізації процесу побудови цільової функції, що визначає рівень техногенної безпеки у БПП. Змістовним висновком із експериментальних досліджень $\epsilon$ збіжність значень пріоритетів факторів та характеристик до певних величин. Для окремих експертів такі величини мають екстремальний характер, але із збільшенням кількості експертів їх сумарні зважені оцінки вирівнюються, що свідчить про їх суб'єктивізм. 
Запропонована технологія $є$ важливим аспектом у створенні інформативних програмних продуктів, 3 допомогою яких можна визначити рівень техногенної безпеки житла у БПП та оптимальні шляхи його зниження. ІЇ̈ можна як конкретизувати для житла на окремих поверхах, так і узагальнити для усього будинку.

\section{Список літератури}

1. Джулай О. М. Еволюційні моделі та методи аналізу і оптимізації рівня пожежної безпеки житлових об'єктів: дис. канд. техн. наук: 05.13.06. Черкаси, 2006.164 с.

2. Грубер И. Эконометрия. Введение в эконометрию. Киев: Алерта, 1996. Т. 1. $434 \mathrm{c}$.

3. Ивахненко А. Г. Юрачковский Ю. П. Моделировение сложных систем по экспериментельным данным. Москва: Радио и связь, 1996. Т. 1.434 с.

4. Хайкин С. Нейронные сети: полный курс. Москва: Вильямс, 2006. 1104 с.

5. Мирошник О. М. Іерархічно-індуктивне моделювання ідентифікації області компромісу між вартістю житла та рівнем його пожежної безпеки. Вісник ВПI. 2009. № 3. C. $46-50$.

6. Снитюк В. Є., Говорухін С. О. Технологія data mining і засоби іiі реалізації. Вicник Черкаського державного технологічного університету. Серія: Технічні науки. 2002. № 3. C. $80-84$.

7. Снитюк В. Є. Прогнозування. Моделі, методи, алгоритми. Київ: Mclaut, 2008. $363 \mathrm{c.}$

8. Саати Т. Принятие решений. Метод анализа иерархий. Москва: Радио и связь, 1993. $278 \mathrm{c}$.

9. Беллман Р., Заде Л. Принятие решений в расплывчатых условиях. В кн.: Вопросы анализа и процедуры принятия решений. Москва: Мир, 1976. С. 172-215.

10. Гнатієнко Г. М., Снитюк В. Є. Експертні технології прийняття рішень. Київ: Mclaut, 2008. 444 c.

11. Снитюк В. Е., Рифат Мухаммед Али. Модели и методы определения компетентности экспертов на базе аксиомы несмещенности. Вісник Черкаського інже- нерно-технологічного інституту. Серія: Технічні науки. 2000. № 4. С. 121-126.

\section{References}

1. July, A. M. (2006) Evolutionary models and methods for analysis and optimization of the level of fire safety of residential properties: thesis for Ph.D. in Engineering: 05.13.06. Gherkasy, 164 p. [in Ukrainian].

2. Gruber, I. (1996) Econometrics. Introduction in econometrics. Kiev: Alerta, Vol. 1, 434 p. [in Russian].

3. Ivakhnenko, A. G., Yurachkovsky, Yu. P. (1996) Modelling of complex systems by experimental data. Moscow: Radio i svyaz, Vol. 1, 434 p. [in Russian].

4. Khaikin, S. (2006) Neural networks: full course. Moscow: Williams, 1104 p. [in Russian].

5. Miroshnik, A. M. (2009) Hierarchicallyinductive modelling for identifying of compromise area between the cost of housing and the level of its fire safety. Visnyk VPI, No. 3, pp. 46-50 [in Ukrainian].

6. Snityuk, V. Ye., Govorukhin, S. A. (2002) Data mining technology and tools for its implementation. Visnyk Cherkaskogo derzhavnogo tehnologichnogo universitetu. Seria: Tehnichni nauky, No. 3, pp. 80-84 [in Ukrainian].

7. Snityuk, V. Ye. (2008) Prediction. Models, methods, algorithms. Kyiv: Mclaut, 363 p. [in Ukrainian].

8. Saati, T. (1993) Decision-making. Hierarchy analysis method. Moscow: Radio i svyaz, 278 p. [in Russian].

9. Bellman, R., Zadeh, L. (1976) Decisionmaking in vague conditions. In: Issues of the analysis and decision-making. Moscow: Mir, pp. 172-215 [in Russian].

10. Gnatienko, G. M., Snityuk, V. Ye. (2008) Expert technologies of decision-making. Kyiv: Mclaut, 444 p. [in Ukrainian].

11. Snityuk, V. Ye., Rifat Mohammed Ali (2000) Models and methods of determining the competence of experts on the basis of the unbiasedness axiom. Visnyk Cherkaskogo inzhenerno-tekhnolohichnogo instytutu. Seria: Tehnichni nauky, No. 4, pp. 121-126 [in Russian]. 
O. M. Miroshnik, Ph.D., associate professor,

associate professor of the department of fire tactics and emergency-rescuer activities

e-mail: omiroshnik@ukr.net

Cherkasy Institute of Fire Safety named after Chornobyl Heroes

of National University of Civil Protection of Ukraine

Onoprienko str., 8, Cherkasy, 18034, Ukraine

\section{TECHNOLOGY OF EXPERT DETERMINATION OF TECHNOLOGICAL SECURITY OF HOUSING IN MULTI-STOREY BUILDINGS}

The low awareness of the population about the level of technogenic security of housing in multi-storey buildings and, as a result, the inadequacy of its price and security characteristics determine the relevance of the development of technology and information-consulting support of the subjects of real estate market (construction and insurance companies, residents, firefighters). The determination of the level of technogenic safety is one of its important elements.

Existing approaches to the definition of the level of technogenic safety do not allow an objective assessment of the safety index for the inhabitants. They take into account the number of internal factors and external characteristics, and do not take into account the priorities of these factors, both empirically and analytically. Therefore, for the solution of this problem, the technology of expert determination of anthropogenic safety level is proposed.

The technology of expert determination of the level of technogenic safety is based on experts' conclusions. The competence of experts can be determined by the decision-maker or by the axiom of unboundedness. As a result, experts' conclusions obtained on the priority of factors will allow to identify the dependence on existing approaches and to establish an indicator of the level of technogenic security analytically.

The proposed technology and pilot studies are an important step towards improving the process of informational and analytical provision of real estate market subjects in the direction of determining the level of technogenic security of housing in multi-storey residential buildings.

The article deals with the problem of determining the level of technogenic security of housing in high-rise buildings. It is proposed to use the expert evaluation, elements of hierarchy analysis method and fuzzy set theory to determine the priority of the factors that influence on the security of housing and are arguments of corresponding target function. The peculiarities of individual and group expert evaluation are determined.

Key words: level of technogenic security, emergency situation, expert evaluation.

Стаття надійшла 14.03.2018.

Рецензенти: $\quad$ В. М. Рудницький, д.т.н., профессор,

О. А. Бужин, д.е.н., профессор. 